should hear more from expert clinicians like F. Kummer. It is important for them to share their wisdom with us.

\section{P.T. Macklem}

Correspondence: P.T. Macklem, Meakins Christie Laboratories, McGill University, Medicine, Montreal, QC, Canada. E-mail: peter.macklem@gmail.com

Statement of Interest: A statement of interest for P.T. Macklem can be found at www.erj.ersjournals.com/misc/statements.dtl

DOI: 10.1183/09031936.00059110

\section{From the authors:}

In our original article we outlined the type of somato-psychosomatic feedback cycle occurring in panic attacks in chronic obstructive pulmonary disease (COPD) that F. Kummer has further elaborated in his correspondence. In fact, this type of feedback cycle is described in the most widely accepted theory of panic attacks and panic disorder in the physically healthy, the cognitive (or "catastrophic interpretation") model [1], and our recent research has supported the applicability of this model to panic in COPD [2-4]. We agree with F. Kummer that some of the most helpful advice respiratory physicians can give their patients with COPD to prevent them entering the feedback cycle of panic is to use "pursed-lip breathing" to help manage their dyspnoea, and to avoid excessive use of shortacting $\beta$-agonists.

We would caution that for individuals with COPD who have already begun to experience panic attacks, for those who have fully developed panic disorder, and even those who are psychologically vulnerable to panic, this sensible advice in isolation will unfortunately not be a sufficient intervention. However, the type of brief, evidence-based psychological intervention that we have reported, when added to comprehensive pulmonary rehabilitation programmes, can help COPD patients to self-manage their own care more effectively [5], treat panic attacks when already present and prevent the development of panic attacks or panic disorder. A more extended psychological intervention will be required for patients who have fully developed panic disorder [3], but without the inherent risks of benzodiazepine medications in the elderly: dependence, cognitive impairment and falls [6].

\section{N. Livermore*, L. Sharpe ${ }^{\#}$ and D.K. McKenzie}

*Liaison Psychiatry, The Prince of Wales Hospital, Randwick,

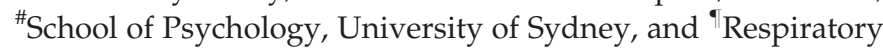
and Sleep Medicine, Prince of Wales Hospital, Sydney, Australia.

Correspondence: N. Livermore, Liaison Psychiatry, The Prince of Wales Hospital, Barker St, Randwick, NSW, 2031, Australia. E-mail: Nicole.Livermore@sesiahs.health.nsw.gov.au

Statement of Interest: None declared.

\section{REFERENCES}

1 Clark D. A cognitive approach to panic. Behav Res Ther 1986; 24 461-470.

2 Livermore N, Butler J, Sharpe L, et al. Panic attacks and perception of inspiratory resistive loads in chronic obstructive pulmonary disease. Am J Respir Crit Care Med 2008; 178: 7-12.

3 Livermore N, Sharpe L, McKenzie D. Cognitive behaviour therapy for panic disorder in chronic obstructive pulmonary disease: two case studies. Behav Cogn Psychoth 2008; 36: 625-630.

4 Livermore N, Sharpe L, McKenzie D. Prevention of panic attacks and panic disorder in COPD. Eur Respir J 2010; 35: 557-563.

5 Bourbeau J, van der Palen J. Promoting effective self-management programmes to improve COPD. Eur Respir J 2009; 33: 461-463.

6 Uchida H, Suzuki T, Mamo D, et al. Benzodiazepine and antidepressant use in elderly patients with anxiety disorders: a survey of 796 outpatients in Japan. I Anxiety Disord 2009; 23: $477-481$

\title{
Inspiratory muscle strength and Borg dyspnoea score
}

\section{To the Editors:}

I read with great interest the paper of JusT et al. [1]. They demonstrated that the Borg dyspnoea scale, particularly assessed in the supine posture, is a useful noninvasive predictor of voluntary respiratory muscle strength tests in patients with amyotrophic lateral sclerosis and has good sensitivity and specificity; however, there a few points that need clarification.

It is known that the pressure values obtained during voluntary respiratory muscle strength tests (maximum sniff and maximal inspiratory and expiratory pressure ( $P \mathrm{I}, \max$ and $P \mathrm{E}, \mathrm{max}$, respectively)) are significantly lower in the supine posture [2].
Thus, it may be more appropriate to correlate the supine Borg with the supine values of those tests, instead of the ones obtained seated. Such a relationship may increase the predictive value of the Borg scale.

It is not clear whether the vital capacity (VC) and the rest of the respiratory muscle strength tests were performed in the upright (standing) or seated posture. At least VC values are expected to be higher in the upright position [3].

In the methods, under the "Pulmonary function tests" section, it is stated that "Static mouth pressure was measured using a flanged mouthpiece [...] at functional residual capacity, as previously described" by BLACK and HyATT [4]. Perusing the 